Penicillin production by the 'gigas' forms in surface culture, using the standard commercial media, appears to be the same as that of untreated controls and camphor-treated controls with spores of average size. It is possible, however, that if 'gigas' forms are obtained
in other strains they may react differently with regard to penicillin production. Furthermore, the behaviour of 'gigas' strains requires testing in deep cuiture media.

Further investigations are being made on the physiology of the 'gigas' strains and also on the question of whether they are actually diploid strains as seems probable.

Department of Cryptogamic Botany,

EVA R. SANSOME University, Manchester. May 23.

1 Bauch, R., Naturwis8., 29, 503 (1941)

Thaysen, A. C., and Muriel Morris, Nature, 152, 526 (1943).

- Levan, Albert, and Gunnar Ostergren, Hereditas, 29, 381 (1943).

\section{Communication Between the Dorsal Edge of the Mantle and the Stomach of Tridacna}

THE part of the mantle edge of Tridacna which is reflected upwards and forwards round the exhalant chamber is highly muscular, greatly thickened and harbours myriads of zooxanthellæ $(7 \mu$ each) in the connective tissue. During the study of the food and feeding habits of this form ${ }^{1}$ it was noticed that appreciable numbers of free zooxanthellø invariably occur in the stomach, especially of big specimens. The presence of zooxanthellæ in the stomach of Tridacna was previously recorded by Boschma ${ }^{2}$ and Yonge ${ }^{3}$. The latter author concluded that such zooxanthellø were introduced accidentally through handling after the animal was opened for examination.

Microscopical examination of serial sections of Tridacna revealed the presence of a remarkable tube system establishing a communicathe presence of a remarkable tube system establishing a communica-
tion between the stomach and the regions of the mantle edge where the zooxanthellæ thrive.

At the stomach end this tube system starts as a single trunk arising medially from the dorsal wall of the stomach. This trunk goes dorsally and posteriorly in the midst of the numerous digestive diverticula. In the dorsal region of the visceral mass it bifurcates to left and right tubes. The accompanying diagram shows the main trunk and righ tube in its full course. The left tube, which is omitted save for a short portion, has a corresponding course. The two tubes run posteriorly fairly close to the muscular septum separating the visceral mass from the greatly enlarged kidneys. Each tube then penetrates the septum, traverses the kidney in a slightly ventral direction and leaves this organ at its posterior third. From the kidneys each tube runs paralle to the gill axis until the region of the adductor muscle, where it swing slightly inwards, to become embedded in the investment of this muscle. With this investment it goes round the posterior surface of the adductor muscle, thus coming to occupy a vertical position. Going round the adductor muscle each tube gives off a main branch which keeps embedded in the investment of the adductor muscle and thus comes to lie in the floor of the exhalant chamber, where it runs forwards almost to the level of the kidneys. It then slants outwards and upward into the side wall of the exhalant chamber until it reaches the thick region of the mantle edge in front of the exhalant opening. Here it divides into two branches ( $a$ and $b$ in diagram) which go to the two anterior lobules of the mantle edge. Fairly close to its point of twin this main branch gives off a very fine one which also runs of origin but remains in the floor of the exhalant chamber. After giving off this first main branch, the tube continues its course, going first to the edge of the investment, from which it passes dorsally into the neigh-

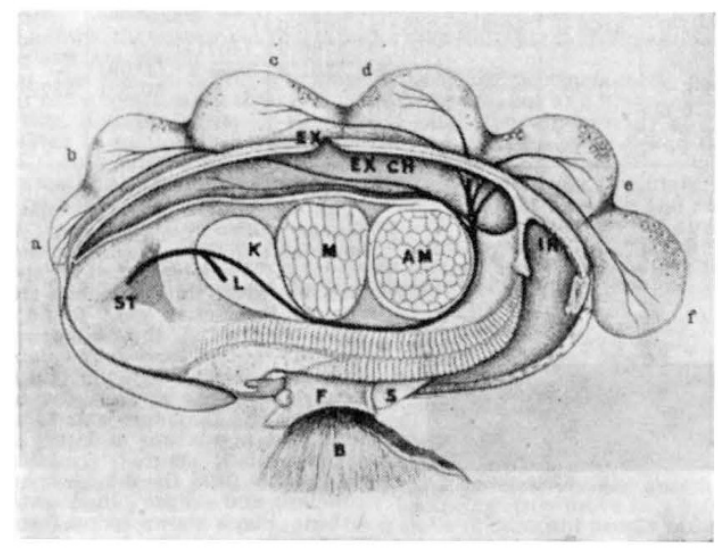

SEMI-DiagRAMMATIC REPREShNTATION OF Tridacna elongata SHOWING THE TRUNK AND THE RIGHT PART OF THE TUBE SYSTEM. THE LEFT MANTLE LOBE TOGETHER WITH ITS VENTRAI AND DORSAI YDDGES IS REMOVED; THE EXHALANT CHAMBER IS SHOWN IN LONGITUDINAL SECTION WITH TTS SPECIAL MUSCLES OMTTTED. $a-f$, branches in the mantle edge ; $A . M$., adductor muscle; $B$., byssus; $E X$., exhalant opening; $E X$. $C H$.', exhalant chamber; left tube; $M$., retractor muscle; $S$. ., inter-branchial septum; ST., stomach. bouring side wall of the exhalant chamber. In this new position it gives off a second main branch which goes to the posterior region of the mantle edge $(f)$. A short distance from the point of origin of this last branch another is given off, which in its turn alsa goes to the
thickened mantle edge $(e)$. In the last stage of its course the tube is embedded in the basal part of the thick edge and here it finally divides into two branches $(c$ and $d)$.

This tube system has a distinct epithelial lining with an equally distinct muscular investment outside it. Its lumen decreases gradually from the trunk to the branches in the mantle edge and naturally varies with the size of the animal. The diameter of the trunk in a specimen
$5 \mathrm{~cm}$. in length is about $200 \mu$. That of the tube just before branching in a specimen $10 \mathrm{~cm}$. in length is $250 \mu$.

In the mantle edge each of the above-mentioned branches terminates in a number of smaller ones which at their ends have very delicate walls which merge insensibly into the delicate connective tissue harbouring the zooxanthellø. This mode of termination also holds good for the flne branch ending in the floor of the exhalant Invariably the Iumen of this tube system contains numerous free zooxanthellæ. No other formed elements or debris have ever been observed mingled with these zooxanthellæ.

The fact that this tube system connects the stomach with the regions of the body where the zooxanthellm are abundant, together with the fact that the zooxanthellm are invariably present in the lumen of this system, indicates that in all probability this tube system is of this system, indicates that in all probability this tube system is the route along which the transport of the zooxanthellm to the stomach
takes place. In the stomach the zooxanthellm showed no signs of being takes place. In the stomach the zooxanthellm showed no signs of being
digested, nor were they ingested. From this region they are passed digested, nor were they ingested. From this region they are passed repeat the cycle.

Details of the histology of this remarkable system, its relation to other systems of the body (especially the hæmocœlic system) as well as its morphological and biological signiflcance will be dealt with elsewhere.

Department of Zoology,

K. MANSOUR

Faculty of Science,

Cairo.

1 Mansour, K., Proc. Egypt. Acad. Sci., 1 (1946) (in the press),

' Boschma, H., Proc. Acad. Sci., Amsterdam, 27, 13 (1924). 1 , No. 11 (1936).

\section{Movements in Culture of some Sewage-Filter Organisms}

SUBMARGINAL banding of various bacteria and protozoa in the covered mounted drop of culture is familiar. It is due to the organisms seeking the zone of optimum oxygen tension. Certain bacteria and some flagellate and ciliate protozoa, also a nematode worm, retire to the cleft below a glass slip placed on the floor of a suitable culture and form bands or other characteristic aggregations. This centripetal movement has appeared in Petri dishes of clear hay and linseed cultures of mixed sewage-fllter organisms. With certain species of ciliates the bands persist for some thirty to flfty days, and the organisms remain abundant in the clefts after they have become very scanty in the open culture.

Paramecium caudatum has been most closely studied and its band remains submarginat, $0.5-1.5 \mathrm{~mm}$. from the edge, for some twenty days. The band then moves inwards and forms a ring farther removed from the margin of the slip. The individuals in the band may number flfty or more to $1.0 \mathrm{~mm}$. of length and the band is distinct to the eye, or they may be sparse. Distance from the margin is not related to density of band. Often they are very orderly, lying touching, aligned in a single row, with the anterior ends inwards. The rather sudden inward migration of the band seems related to an advanced stage in flocculation of the culture bacteria
becomes available to the ciliates.

When slips $22 \mathrm{~mm}$. square were raised on feet to give clefts graded in height from virtual 0 to $1.12 \mathrm{~mm}$. it was found that the highest cleft was scarcely attractive to Paramecium. A cleft of $1.0 \mathrm{~mm}$. attracted large numbers, but inward movement was continuous and relatively rapid and complete dispersal occurred when the culture was fourteen days old. Clefts of $0.15-0.55 \mathrm{~mm}$. attracted numbers in proportion to height and the agregations in each followed the same course but at speed directly related to height. This course was: same course but at speeds directly related to height. This course was : uniform uniform cloud, and finally uniform dispersal in the clefts of numbers phase was reached with a cleft of $0.55 \mathrm{~mm}$. in 32 days, and with a cleft of $0.35 \mathrm{~mm}$. in 41 days, when there was still a slight central cleft of $0.35 \mathrm{~mm}$. in 41 days, wher

aggregation in a cleft of $0.15 \mathrm{~mm}$.
It is clear that some factor additional to oxygen requirement is influencing this reaction; this appears to be the attraction of carbon dioxide trapped in the clefts below the sunken slips. Carbon dioxide and other weak acids are known to attract Paramecium, and conditions in the clefts are more acid than in free culture. Further, if the bulk of the culture is removed, charged with carbon dioxide and returned to the dish without disturbing the slip, there is no mechanical disturbance of the band, but within an hour it disperses completely, conditions in the open culture being now more acid than in the cleft. On the other hand, if the fluid withdrawn is aerated and returned, the band intensifles.

It is supposed that this retiring habit occurs in Nature and must be of importance to organisms of this type in fluctuating waters. Especially should this be the case in sewage filters with their intermittent wettings, for moisture is held in the narrow clefts when the

$$
\text { University of Leeds. }
$$

